\title{
Cycling as a Part of Recreation: An Awareness-Exploring Study
}

\author{
Merve Uca (Corresponding author) \\ Department of Physical Education and Sports Teaching, Faculty of Sport Sciences \\ Istanbul Aydin University, 34295, Istanbul, Turkey \\ Tel: 444-1-428-27502Ｅ-mail: merveuca@aydin.edu.tr
}

Leyla Alizadehebadi

Department of Coaching Education, Faculty of Sport Sciences

Istanbul Aydin University, 34295, Istanbul, Turkey

Tel: 444-1-428-68702Ｅ-mail: leylaalizadehebadi@aydin.edu.tr

Sevim Handan Y1lmaz

Department of Physical Education and Sports Teaching, Faculty of Sport Sciences

Gazi University, 06210, Ankara, Turkey

E-mail: handanyilmazz@hotmail.com

Received: November 5, 2021 Accepted: November 29, 2021

Published: December 31, 2021

doi:10.5296/jei.v7i3.19152 URL: https://doi.org/10.5296/jei.v7i3.19152

\begin{abstract}
This study aimed to explore the awareness among individuals engaged in recreational cycling about the benefits of cycling. The study consists of 66 participants in the age group of 18-30 who are interested in recreational cycling in the province of Sakarya. The "Recreation Awareness Scale" developed by Ekinci and Özdilek (2019) was used as a data collection tool in the study. In the study, skewness and kurtosis (kurtosis) were evaluated to ensure the normal distribution of the data in addition to descriptive statistical methods such as percentage and frequency. As a result, we found the data to be normally distributed and, thus, utilized the parametric tests. Accordingly, the groups were compared using a t-test and an
\end{abstract}


analysis of variance (ANOVA). In addition, we performed a Tukey test to find out the group(s) as the source of difference. Then, Pearson's correlation analysis was performed to see the association between two continuous variables. The results revealed that the participants did not differ significantly on pleasure/entertainment, social/achievement, and self-development subscales by gender. Yet, the mean scores of the participants differed significantly on the social/achievement and self-development subscales by educational attainment. The post hoc test suggested that those having a high school degree got significantly higher scores on the social/achievement subscale than the participant with an associate degree. Moreover, the high school graduates obtained higher scores on the self-development subscale than those with a secondary school, associate, and undergraduate degree. Considering the relationship between recreation awareness and age, the Pearson's correlation test revealed significant positive relationships between age and the participants' scores on the social/achievement and self-development subscales. Yet, we could not find a significant relationship between age and the pleasure/entertainment subscale.

Keywords: Recreation, Leisure time, Awareness, Benefits, Sports

\section{Introduction}

Cycling, which has an important place among the types of physical activity, provides many benefits to its participants (Biernat et al., 2018). In addition to recreational activities (Cavill et al., 2008; De Hartog et al., 2010), it may provide considerable flexibility compared to other modes of transport (Akar \& Clifton, 2009) and also increases social cohesion by making commuting economical (Gatersleben \& Appleton, 2007). On the other hand, from the perspective of transportation and physical activity, cycling offers ways to contribute significantly to health and longevity in terms of cost (De Hartog et al., 2010; Oja et al., 2011; Reynolds et al., 2010). In summary, from a public perspective, cycling plays an effective role in reducing transportation-related costs by significantly reducing carbon emissions, as well as reducing traffic congestion and other external environmental pollution (De Geus et al., 2009).

Individuals used to spend physical performance even for their daily work before the industrial revolution. However, individuals now enjoy convenience in their daily lives thanks to the rapid advancement of technology, which allows individuals to spare time for them. Smith (1987) considers the concept of recreation as one of the fundamental needs of individuals and conceives of it within activities providing satisfaction at an optional time. Besides, Stebbins (2016) defines recreational activities as all the entertaining, satisfying activities that individuals in outside of working hours without any coercion, where they use their own resources, and whose boundaries are determined within a specific framework. Based on such definitions, all activities, such as cycling, flying a kite, or playing digital games, are described as either leisure or recreational activities (Russell, 2017). In this context, it can be asserted that individuals gain many benefits as a result of their participation in recreational activities, boosting the importance of such activities (Manfredo et al., 1996).

The benefits from recreational activities are categorized as physiological, social, psychological, and emotional benefits. Physiological benefits can be considered as protection of health, protection from physical disorders, improved fitness, increased productivity, 


\section{Macrothink}

elevated engagement in work, and decreased health expenses. Regarding their psychological benefits, individuals may enjoy reduced stress and elevated happiness. Encouraging communication, cooperation, and harmony can be listed among the social benefits of recreational activities. Finally, such activities have significant emotional benefits in terms of creating leisure behavior values (Cordes \& İbrahim, 1999).

Mannell and Stynes (1991), on the other hand, examined the benefits of participation in recreational activities under twenty-one categories; a few of these categories are psychological benefits, physiological benefits, environmental benefits, and social and economic benefits. Ultimately, being informed and aware of such gifts of participating in recreational activities is conceptualized as recreational awareness. Recreational awareness - one's awareness of the benefits of recreational activities - occupies an essential place in recreational participation and the selection of activities. As a matter of fact, preferring and participating in recreational activities consciously are more likely to provide significant personal and social benefits (Ekinci, 2017). In a study on cyclists engaged in outdoor recreation, the participants reported doing this activity for reasons such as being in nature and being healthy and, thus, feeling even happier, healthier, and relaxed (Ardahan \& Lapa, 2011). In this perspective, we aimed to explore recreational awareness among cyclists.

\section{Method}

While the research universe covered those interested in cycling for recreational purposes in Sakarya city, the sample was composed of 66 participants interested in cycling and aged 18-30 years.

We collected the main data using the Recreation Awareness Scale (RAS) developed by Ekinci and Ozdilek (2019). It is a 41-item tool within three subscales (Pleasure/entertainment, Social/achievement, and Self-development) and rated on a 5-point Likert-type scale ranging from 1 (Strongly disagree) to 5 (Strongly agree).

\subsection{Data Collection}

We analyzed the data using the SPSS 25 package program. The descriptive data were presented as percentages and frequencies. We checked skewness and kurtosis values to reveal whether the quantitative data showed a normal distribution. As a result, we found the data normally distributed and, thus, utilized the parametric tests. Accordingly, the groups were compared using a t-test and an analysis of variance (ANOVA). In addition, we performed a Tukey test to find out the group(s) as the source of difference. Then, we performed a Pearson's correlation analysis to see the association between two continuous variables. In all statistical analyses, we considered $\mathrm{p}<0.05$ to be significant. 


\section{Results}

Table 1. Distribution of the participants' demographic characteristics

\begin{tabular}{|l|l|l|l|}
\hline Variables & & N & $\%$ \\
\hline \multirow{5}{*}{ Gender } & Male & 40 & 60.6 \\
\cline { 2 - 4 } & Female & 26 & 39.4 \\
\cline { 2 - 4 } & Total & 66 & 100 \\
\hline \multirow{5}{*}{ Educational attainment } & Secondary school & 12 & 18.2 \\
\cline { 2 - 4 } & High school & 19 & 28.8 \\
\cline { 2 - 4 } & Associate degree & 8 & 12.1 \\
\cline { 2 - 4 } & Undergraduate & 21 & 31.8 \\
\cline { 2 - 4 } & Postgraduate & 6 & 9.1 \\
\cline { 2 - 4 } & Total & 66 & 100 \\
\hline \multirow{5}{*}{ Age } & 20 years and below & 18 & 27.3 \\
\cline { 2 - 4 } & $20-30$ years & 30 & 45.5 \\
\cline { 2 - 4 } & 30 years and over & 18 & 27.3 \\
\cline { 2 - 4 } & Total & 66 & 100 \\
\hline
\end{tabular}

As in Table 1, the majority of the participants $(60.6 \%)$ were males. While $28.8 \%$ of the participants had an undergraduate degree, about half of them (45.5\%) were 20-30 years.

Table 2. Participants' scores on the RAS by gender

\begin{tabular}{|c|c|c|c|c|c|c|c|}
\hline & Subscales & Groups & $\mathrm{N}$ & Mean & $\mathrm{SD}$ & $\mathrm{t}$ & $\mathrm{p}$ \\
\hline \multirow{6}{*}{ Gender } & \multirow{2}{*}{ Pleasure/entertainment } & Male & 40 & 4.56 & 0.42 & \multirow{2}{*}{0.259} & \multirow{2}{*}{0.797} \\
\hline & & Female & 26 & 4.53 & 0.43 & & \\
\hline & \multirow{2}{*}{ Social/achievement } & Male & 40 & 4.28 & 0.47 & \multirow{2}{*}{-0.413} & \multirow{2}{*}{0.681} \\
\hline & & Female & 26 & 4.32 & 0.44 & & \\
\hline & \multirow{2}{*}{ Self-development } & Male & 40 & 4.42 & 0.47 & \multirow{2}{*}{0.430} & \multirow{2}{*}{0.669} \\
\hline & & Female & 26 & 4.37 & 0.47 & & \\
\hline
\end{tabular}




\section{Macrothink}

The participants did not differ significantly in their scores on the subscales by gender $(p>$ $0.05)$.

Table 3. Participants' scores on the RAS by educational attainment

\begin{tabular}{|c|c|c|c|c|c|c|c|}
\hline Subscales & Educational attainment & $\mathrm{N}$ & Mean & SD & $\mathrm{F}$ & $\mathrm{p}$ & Tukey test \\
\hline \multirow{5}{*}{ Pleasure/Entertainment } & Secondary school & 12 & 4.65 & 0.38 & \multirow{5}{*}{2.33} & \multirow{5}{*}{0.065} & \\
\hline & High school & 19 & 4.62 & 0.39 & & & \\
\hline & Associate degree & 8 & 4.25 & 0.34 & & & \\
\hline & Undergraduate & 21 & 4.46 & 0.48 & & & \\
\hline & Postgraduate & 6 & 4.81 & 0.24 & & & \\
\hline \multirow{5}{*}{ Social/Achievement } & Secondary school & 12 & 4.24 & 0.36 & \multirow{5}{*}{3.22} & \multirow{5}{*}{$0.018 *$} & \multirow{5}{*}{ High school-Associate degree } \\
\hline & High school & 19 & 4.52 & 0.46 & & & \\
\hline & Associate degree & 8 & 4.29 & 0.28 & & & \\
\hline & Undergraduate & 21 & 4.19 & 0.48 & & & \\
\hline & Postgraduate & 6 & 4.52 & 0.41 & & & \\
\hline \multirow{5}{*}{ Self-development } & Secondary school & 12 & 4.28 & 0.39 & \multirow{5}{*}{5.40} & \multirow{5}{*}{$0.001 * *$} & \multirow{5}{*}{$\begin{array}{l}\text { High school-Secondary school, } \\
\text { High school-Associate degree, } \\
\text { High school-Undergraduate }\end{array}$} \\
\hline & High school & 19 & 4.72 & 0.41 & & & \\
\hline & Associate degree & 8 & 4.14 & 0.30 & & & \\
\hline & Undergraduate & 21 & 4.21 & 0.46 & & & \\
\hline & Postgraduate & 6 & 4.66 & 0.38 & & & \\
\hline
\end{tabular}

Note. ${ }^{*} \mathrm{p}<.05$.

As in Table 4, there were no significant differences between the participants on the pleasure/entertainment subscale by educational attainment $(p>0.05)$. Yet, their mean scores differed significantly on the social/achievement and self-development subscales by educational attainment $(\mathrm{p}<0.05)$. The post hoc test suggested that those having a high school degree got significantly higher scores on the social/achievement subscale than the participant with an associate degree. Moreover, the high school graduates obtained higher scores on the self-development subscale than those with a secondary school, associate, and undergraduate degree.

Considering the relationship between recreation awareness and age, the Pearson's correlation test revealed significant positive relationships between age and the participants' scores on the social/achievement and self-development subscales $(\mathrm{p}<0.05)$. Yet, we could not find a 
significant relationship between age and the pleasure/entertainment subscale.

\section{Discussion}

In the present study, we aimed to explore the awareness of individuals engaged in recreational cycling about the benefits of cycling. In the literature on recreational awareness, Mannell and Stynes (1991) previously examined the benefits of participation in recreation in 21 subcategories, including psychological, physiological, environmental, and social and economic benefits. Driver (1990) similarly touched on the physical, psychological, and social benefits of participating in recreation. One's awareness of such benefits may play an active role in their participation in recreation and engagement in activity selection (Dustin, 1997).

Most cyclists are among those who are disadvantaged economically, less educated, and residents in rural areas; namely, they have no other possibility in transportation. According to macro statistics, the prevalence of cycling to and from work is negatively associated with the use of cars or public transport (Dill \& Carr, 2003; Parkin et al., 2008). The role of necessity and economic constraints also explains why the share of cycling deviates from the well-known positive correlation pattern between cycling prevalence and residential density (Heinen et al., 2010). Overall, the evidence for the relationship between income and cycling is rare, and there is no reason to expect cycling or the modal share of bikes to differ between income groups (Heinen et al., 2010; Pucher \& Buehler, 2008).

In fact, only a fraction of cyclists is compelled to use the bike, a finding consistent with other research. Damant-Sirois et al. (2014), Willis et al. (2013), Gatersleben and Haddad (2010), and Jensen (1999) previously derived similar results on motivation and attitudes regarding cyclists segmentation. The categories of cyclists listed by the researchers are essential (or necessity), lifestyle, commuter, and convenience (or leisure) cyclists. The second study seems to be the most relevant comparison as it uses clustering in a similar way to our study. The actions to cycle and increase cycling frequency should also be different because of the diverse motivation sources. We share such an insight with Damant-Sirois et al. (2014), Gatersleben and Haddad (2010), and Jensen (1999).

It is apparent that cyclists often utilize facilities at work or school better than others; yet, the direction of causality here is still unclear. Cyclists, in particular, tend to view infrastructure barriers as more important (Hunt \& Abraham, 2007). Moreover, there is an expectation problem - cycling tends to be less enjoyable than expected, but such a disadvantage is compensated by the surprising flexibility of cycling as a mode of transport (Gatersleben \& Appleton, 2007).

While the local area's overall cycling-friendliness recorded somewhat similar remarks among dedicated cyclists and others, the availability of facilities at work or school varies considerably. According to the literature, the basic infrastructure includes all types of bike parking, cloakrooms, individual lockers, and showers (Biernat et al., 2018). The rest is perceived as unimportant or not considered at all (e.g., repair stations are often provided by local governments) (Abraham et al., 2002; Heinen et al., 2010; Hunt \& Abraham, 2007). Although this variation is to some extent attributed to a lack of awareness among non-cycling 
individuals, the statistical significance is exceptionally high. Therefore, it should be made clear that the availability of at least fundamental facilities is associated with the popularity of cycling. Unfortunately, causality is again impossible to prove (Damant-Sirois et al., 2014).

The final question is about policies and factors that could increase the share of cycling in commuting. Cycling infrastructure and road safety should be a priority for the participants themselves - nowhere else is there such a big difference between the expectations of cyclists and non-cyclists (Biernat et al., 2018). This confirms earlier results from multiple studies and from different countries (for a full review, see Heinen et al., 2010) but cannot provide a complete picture. First, encouraging non-cyclists to cycle and promoting active cyclists to increase their cycling frequency require different means (Gatersleben \& Appleton, 2007; Heinen et al., 2010). Secondly, it is vital to increase the relative attractiveness of this mode of transport for those who try or do cycling occasionally. One can achieve this either by smoothing the journey and shortening its duration or increasing safety if thoroughly segregated traffic is not feasible (Gatersleben \& Appleton, 2007).

Still, the robustness of our conclusions is limited by several factors. First, the study is a cross-sectional study, and, therefore, we cannot establish causality. Without a longitudinal setting, we are also unable to assess whether the reported barriers to cycling actually result in the decision to commute by bike. Secondly, the dataset we use is mainly based on subjective responses to the questions

The purpose of this paper was to provide a detailed picture of cyclists as well as to analyze their motivations and barriers to cycling. The results should assist policymakers in promoting cycling as a form of leisure activity in Turkey and facilitate solving other problems such as air pollution and urban congestion. We also think that the results may contribute to the available literature in several important ways. Moreover, by associating the classification of cyclists with socio-economic variables, we may create recommendations tailored to the specific needs of the groups identified in our analysis.

\section{Conclusion}

Cycling is an occasionally preferred activity in Turkey. Not only is cycling low in prevalence, but it is also rarely the dominant mode of transport. In most cases, frequent use is not a matter of choice but primarily due to scarce resources. The current development of bike-sharing systems and increasing accessibility to infrastructure will most likely be the first step towards this goal. The progress of cycling should be monitored, as it can be perceived as a solution to a wide range of problems in Turkey, such as lack of leisure time activities, congestion, or air pollution.

As a result of the research, we determined that recreational awareness did not differ by gender. In the social/achievement and self-development subscales, the mean scores of the participants having a high school degree were significantly higher than those with a secondary school and associate degree. Moreover, we found that the mean scores on the social/achievement and self-development subscales significantly increased by age. 


\section{Limitations and Recommendations}

This study inevitably has some limitations. First, it is limited to the age, educational attainment, and gender of those regularly cycling for recreational purposes in Sakarya city. Future research on this subject may consider various cultural variables to determine the differences between individuals engaged in recreational cycling. Secondly, other demographic factors, such as economic well-being and lifestyles, may affect awareness levels among individuals. Therefore, protective researchers may explore in-depth the upbringing conditions of cyclists, attitudes in their families and environments, and their knowledge on the positive impacts of recreation.

\section{References}

Abraham, J. E., McMillan, S., Brownlee, A. T., \& Hunt, J. D. (2002). Investigation of cycling sensitivities. 81st Annual Meeting of the Transportation Research Board. Washington, DC: Transportation Research Board.

Akar, G., \& Clifton, K. (2009). Influence of individual perceptions and bicycle infrastructure on decision to bike. Transportation Research Record: Journal of the Transportation Research Board, 2140(1), 165-172. https://doi.org/10.3141/2140-18

Ardahan, F., Lapa, Y. T. (2011). Outdoor recreation: the reasons and carried benefits for attending outdoor sports of the participants of cycling and/or trekking activities. International Journal of Human Sciences, 8(1), 1328-1341.

Biernat, E., Buchholtz, S., \& Bartkiewicz, P. (2018). Motivations and barriers to bicycle commuting: Lessons from Poland. Transportation Research Part F, 55, 492-502. https://doi.org/10.1016/j.trf.2018.03.024

Cavill, N., Kahlmeier, S., Rutter, H., Racioppi, F., \& Oja, P. (2008). Economic analyses of transport infrastructure and policies including health effects related to cycling and walking: A systematic review. Transport Policy, 15(5), 291-304. https://doi.org/10.1016/j.tranpol.2008. 11.001

Cordes, K. A., \& Ibrahim, H. M. (1999). Application in Recreation and Leisure for Today and the Future. Boston: McGraw-Hill.

Damant-Sirois, G., Grimsrud, M., \& El-Geneidy, A. M. (2014). What's your type: A multidimensional cyclist typology. Transportation, 41(6), 1153-1169. https://doi.org/10.1007/ s11116-014-9523-8

De Geus, B., De Bourdeaudhuij, I., Jannes, C., \& Meeusen, R. (2007). Psychosocial and environmental factors associated with cycling for transport among a working population. Health Education Research, 23(4), 697-708. https://doi.org/10.1093/her/cym055

De Hartog, J. J., Boogaard, H., Nijland, H., \& Hoek, G. (2010). Do the health benefits of cycling outweigh the risks? Environmental Health Perspectives, 118(8), 1109. https://doi.org/ 10.1289/ehp.0901747 


\section{Macrothink}

Journal of Educational Issues ISSN 2377-2263

Driver, B. L. (1990). The North American experience in measuring the benefits of leisure. In E. Hamilton-Smith (Ed.), Proceedings, National Workshop on Measurement of Recreation Benefits (pp. 1-57). Philip Institute of Technology, Bandoora, Australia.

Dustin, D. L., \& Goodale, T. L. (1997). The social cost of individual benefits. Parks \& Recreation, 32(7), 20-22.

Ekinci, N. E. (2017). Investigating of University Students Awareness about Recreational Activities (Dumlupinar University Health Sciences Institute, Department of Physical Education and Sports, Post Graduate Thesis, Kutahya).

Ekinci, N. E., \& Ozdilek, C. (2019). Investigation of university students' awareness of recreational activities. International Online Journal of Educational Sciences, 11(2), 53-66. https://doi.org/10.15345/iojes.2019.02.004

Gatersleben, B., \& Appleton, K. M. (2007). Contemplating cycling to work: Attitudes and perceptions in different stages of change. Transportation Research Part A: Policy and Practice, 41(4), 302-312. https://doi.org/10.1016/j.tra.2006.09.002

Gatersleben, B., \& Haddad, H. (2010). Who is the typical bicyclist? Transportation Research Part F: Traffic Psychology and Behaviour, 13(1), 41-48. https://doi.org/10.1016/j.trf.2009. 10.003

Götschi, T., Garrard, J., \& Giles-Corti, B. (2016). Cycling as a Part of Daily Life: A Review of Health Perspectives, Transport Reviews, 36(1), 45-71. https://doi.org/10.1080/01441647. 2015.1057877

Heinen, E., Van Wee, B., \& Maat, K. (2010). Commuting by bicycle: An overview of the literature. Transport Reviews, 30(1), 59-96. https://doi.org/10.1080/01441640903187001

Hunt, J. D., \& Abraham, J. E. (2007). Influences on bicycle use. Transportation, 34(4), 453-470. https://doi.org/10.1007/s11116-006-9109-1

Kleiber, D. A. (1987). Why People Recreate. Smith, David H. \& Theberge, Nancy. Journal of Leisure Research, 19(3), 242-243. https://doi.org/10.1080/00222216.1987.11969693

Manfredo, M. J., Driver, B. L., \& Tarrant, M. A. (1996). Measuring leisure motivation: A meta analysis of the recreation experience preference scales. Journal of Leisure Research, 28(3), 188-213. https://doi.org/10.1080/00222216.1996.11949770

Mannell, R. C., \& Stynes, D. J. (1991). A retrospective: The benefits of leisure. Benefits of Leisure, 16, 461-473.

Oja, P., Titze, S., Bauman, A., de Geus, B., Krenn, P., Reger-Nash, B., \& Kohlberger, T. (2011). Health benefits of cycling: A systematic review. Scandinavian Journal of Medicine \& Science in Sports, 21(4), 496-509. https://doi.org/10.1111/j.1600-0838.2011.01299.x

Reynolds, C., Winters, M., Ries, F., \& Gouge, B. (2010). Active transportation in urban areas: Exploring health benefits and risks. National Collaboration Centre for Environmental Health. 
Russell, R. V. (2017). Pastimes: The context of contemporary leisure (6th ed.). IL, ABD: Sagamore Publishing.

Stebbins, R. A. (2016). The serious leisure perspective or the leisure experience perspective? A rejoinder to Veal. Research Gate. https://doi.org/10.13140/RG.2.2.31471.23203

Tabachnick, B., \& Fidell, L. (2013). Using multivariate statistics (6th ed.). New Jersey: Sage Publications, Thousand Oaks.

\section{Copyright Disclaimer}

Copyright for this article is retained by the author(s), with first publication rights granted to the journal.

This is an open-access article distributed under the terms and conditions of the Creative Commons Attribution license (http://creativecommons.org/licenses/by/3.0/). 